\title{
Consequences of oncogenic isocitrate dehydrogenase mutations and 2-hydroxyglutarate production in prostate epithelium
}

\author{
Jon A Over", Jonathan D Licht \\ From Epigenetics \& Chromatin: Interactions and processes \\ Boston, MA, USA. 11-13 March 2013
}

\section{Background}

Recent technological advances in DNA sequencing have yielded more comprehensive identification of mutations occurring in tumors. These efforts have detected recurrent mutations in a gene encoding isocitrate dehydrogenase (IDH1) in several tumor types including prostate cancer. In each of these tumors IDH1 missense mutations at arginine 132 (R132) confer a gain of function and produce an aberrant metabolite, 2-hydroxyglutarate (2HG) as opposed to wild type (WT) activity that produces alpha-ketoglutarate (a-KG). a-KG is a cofactor for the Ten-Eleven Translocation enzymes (TET1/2/3), which catalyze DNA hydroxymethylation. Although this DNA modification is predicted to affect epigenetic regulation, its specific effects and target genes remain unclear. We hypothesize that 2HG produced by mutant IDH1 promotes tumor phenotypes through mechanisms directly affecting DNA hydroxymethylation.

\section{Materials and methods}

We tested our hypothesis in a cell culture model using RWPE cells, which were derived from a histologically normal adult human prostate. These cells were infected with retrovirus co-expressing green fluorescent protein together with either WT or R132H alleles of IDH1. 2HG levels were quantified by a fluorometric assay that measures NADH produced by $2 \mathrm{HG}$-dehydrogenase. DNA hydroxymethylation was measured in genomic DNA samples by dot blots with immunodetection using a rabbit polyclonal antibody (Active Motif \#39770). Gene expression was measured by quantitative-PCR on cDNA prepared from total RNA isolations. Cell proliferation was evaluated by measuring cellular conversion of methylthiazolyldiphenyltetrazolium (MTT) to purple-colored formazan that is quantified by measuring absorbance at $\lambda=600 \mathrm{~nm}$.

\section{Results}

RWPE cells expressing the R132H mutant produced 2HG at levels comparable to those measured in cancer cell lines with endogenous IDH1 mutations, whereas $2 \mathrm{HG}$ was not generated by IDH1 WT overexpression. Relative to WTexpressing or uninfected cells we observed that global DNA hydroxymethylation was reduced in $\mathrm{R} 132 \mathrm{H}$-expressing cells. Moreover, our data suggest that this trend increases with duration of $\mathrm{R} 132 \mathrm{H}$ expression. Reduced DNA hydroxymethylation likely results from inhibition of TET2 and/or TET3, because TET1 expression was not detected in RWPE cells. Despite molecular changes associated with IDH1 R132H expression, proliferation was not affected when cells were cultured in complete media. However, 2HG conferred a growth advantage to RWPE cells cultured with reduced growth factor levels.

\section{Conclusions}

Production of 2HG by mutant IDH1 expression was sufficient to reduce global levels of DNA hydroxymethylation in prostate epithelial cells. Moreover, these cells exhibited increased proliferation upon 2HG exposure when cultured in media with diminished growth factors, which is intended to better mimic resource limitations of tumor growth. Collectively these findings improve our understanding of how IDH1 mutations promote carcinogenesis with the goal of developing effective targeted therapies against IDH1 mutant tumors. 


\section{Acknowledgements}

Funding for this research was provided by the DeBoer Family Foundation and Northwestern University Physical Sciences-Oncology Center. We would also like to thank Drs. Jörg Balss and Andreas von Deimling of Universität Heidelberg for generously providing reagents required for $2 \mathrm{HG}$ quantification.

Published: 8 April 2013

doi:10.1186/1756-8935-6-S1-P120

Cite this article as: Over and Licht: Consequences of oncogenic

isocitrate dehydrogenase mutations and 2-hydroxyglutarate production in prostate epithelium. Epigentics \& Chromatin 2013 6(Suppl 1):P120.

Submit your next manuscript to BioMed Central and take full advantage of:

- Convenient online submission

- Thorough peer review

- No space constraints or color figure charges

- Immediate publication on acceptance

- Inclusion in PubMed, CAS, Scopus and Google Scholar

- Research which is freely available for redistribution

Submit your manuscript at www.biomedcentral.com/submit
() Biomed Central 